\title{
Big Brother is looking after your health
}

\author{
Richard Turner
}

In the corner of the supermarket David Jones looked for the row of telephone boxes, each one with a curtain, a stool, and a white illuminated screen, like the photography booths to be found on every station platform apart from the fact that these contained red telephones. He took a seat in one and lifted the handset to talk to the computer doctor.

The friendly voice at the other end of the line thanked him for calling and asked him for his name and address. He smiled to himself as he gave the details because, although the voice had a slight Devonshire accent, as well it might for a telephone in Taunton, he knew that it only wanted him to say something so that it could identify him from his voice print. The fact that he lived $400 \mathrm{~km}$ away in Harrogate would make no difference. It, or the National Health Computer System to which it was connected, was an old friend. $\mathrm{He}$ and his sister had been registered with it by the midwife on the day they were born, as had their parents and grandparents before them. It knew every detail of the medical histories of everyone on their family tree for three generations, not to mention where each of them was living now (through its connection with the National Tax and Allowance System) and, from the National Death Registration System, the causes of death of those no longer alive.

"Good afternoon. How are you, David?" it asked. He told it about the pain in his stomach which had kept him tossing and turning all night, and he knew that while he was talking the telephone would be taking samples of his breath from the mouthpiece and analysing them for anything that might remotely be relevant to his complaint. At the same time the thin gold bands round the handset would be recording the faint electrical signals generated by his heart (the other electrode being the metal bar he was holding to steady himself), and the stool he sat on would be weighing him.

"When did the pains start?" the computer asked as ultrasound beams emerged noiselessly from the dark panel in front of him, bounced off every organ in his chest and abdomen, and were recorded by detectors behind the panel. He said that they had started at midnight, and that he had vomited once or twice.

"Interesting," said the voice. "You had something like that a few years ago, didn't you?"

"Ah, but that was different," he said. He remembered that night well. Both he and his wife had vomited all night after visiting a restaurant. "That was in 1999 , and Laura had got it too. You diagnosed food poisoning and we recovered after 12 hours of eating nothing and drinking only water, as you predicted."

The machine noted that his voice was steady and that his memory was good, and it measured his pulse rate and blood pressure from sensors built into the telephone handset he was holding.

"Might it have anything to do with your visit to Nigeria last week?" it asked, examining his breath to see if it could detect the metabolic products of the antimalarial drugs prescribed beforehand. It knew that he had made the trip from an electronic inquiry to the International Airline Booking Computer, and from an inquiry to Inter-Credit that he had had meals in several restaurants there.

"No, I don't think so," said David, who had been a guest of the government and had only stayed a few days, mainly in air conditioned hotels.

"Well, your temperature is up a bit," said the computer after checking another sensor in the handset. "Can you read the message on the screen in front of you?" David looked, but the letters were too small. "You need glasses," said the machine, enlarging the size of the typeface. He could then read the message, which said, "Look at the black dot in the centre of the screen."

David did as he was told and kept his gaze fixed on the spot while a beam of light shone into his eyes.

"Ha!" said the computer to itself. It found that David's retinas were normal and did not proceed with visual field or intraocular pressure tests on this occasion, having carried these out less than a year ago, but it noted that the whites of his eyes were yellowish rather than white.

"Where exactly is the pain in your abdomen?"

"On the right hand side, just under my ribs," said David. "I can put my finger on it."

\section{Diagnosis and treatment}

The computer asked a few more questions and carried out a few more analyses on his breath to exclude other possible causes of abdominal pain. It then compared the pattern of symptoms and signs obtained from David with those in the National Databank and noted that the most probable diagnosis was cholecystitis. It looked through his family history.

"I think you have an infected gall bladder," it said. "I see that both your great grandmother and one of your aunts had their gall bladders taken out in their day. Yours is quite large and is full of gall stones, although quite a few people have those without getting any symptoms." It consulted the National Databank again to discover what form of treatment yielded the best results in patients with the same age, sex, and symptom pattern as David.

"Luckily, it should be possible to do something about that without surgery these days. Go over to the pharmacy dispenser and take the pills it will give you according to the instructions on the packet. Then come back here again in three days." As David stood up, sensors measured his height and computed his body mass index.

David did as he was told, placing his hand on the pad on the pharmacy machine for fingerprint recognition and for authorisation of the amount of money indicated on the screen to be debited from his bank accout. He knew that he soon would be over the age limit for charges, and that this type of message at least would no 


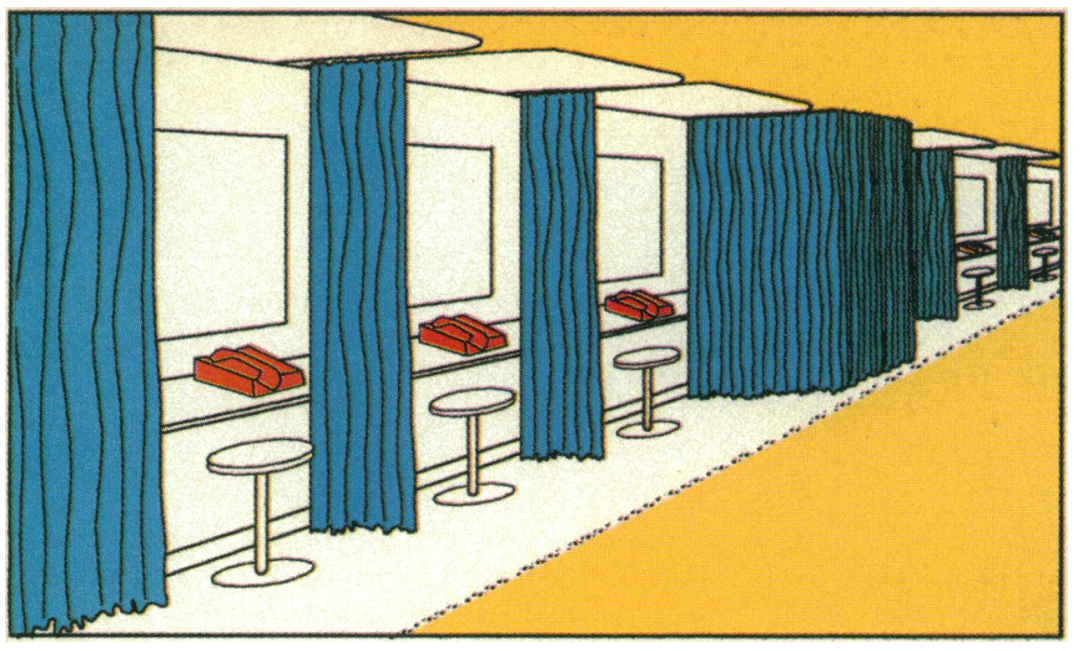

Futuristic, but possible: the Mediphone

longer appear. A little packet fell into the box below the screen, together with a card inviting him to go to the optician's counter to have a more detailed visual check and to select a pair of spectacle frames. He felt ill, however, and went home to bed.

Three days later, back at home in north Yorkshire, the telephone rang in the evening.

"You haven't been back to a Mediphone booth," said the voice from Devon. "Are you feeling better?"

David felt guilty. "Much better," he said. "I haven't finished the course of tablets yet, and thought I would leave it until I had since they are obviously working."

"OK," said the voice at the end of the line. It knew from his family history and from his exam results both in school and university (as recorded by the Central Educational Bureau) that he was intelligent. However, from previous responses to requests to attend the Mediphone booth it knew that he was rather unreliable in this respect. "Do go back though," it said. "The pills you are on now are only antibiotics designed to get rid of the infection. Once that is dealt with you will need some others to dissolve the gall stones. You could also do with losing some weight." It did not mention that the electrocardiogram showed very early signs of ischaemic damage to the heart which would be worth following up, particularly in view of a strong family history of coronary artery disease evident from the genetic record. Luckily there had been no traces of nicotine on David's breath.

The computer updated the neural network in the National Databank to pass on all the knowlege it had about David and what treatment it had recommended for him, together with the fact that the abdominal pain had resolved within three days. Further follow up details could be sent in when David next came to the Mediphone. Keeping the central network up to date was important in order to determine which forms of treatment worked best for particular groups of patients.

"OK," said David, knowing that he might decide not to go back, but also that he would have to tell the Mediphone of his decision if he did not want to be pestered by one phone call after another. He also knew that his employer might ask him to produce a clean Mediphone "bill of health" if he took many more days off work and that, although the computer would not tell his employer the diagnosis, it would not tell a lie and say that he was doing all he could to keep healthy if he ignored its suggestions.

Finally, there was the matter of the optician card and the need to get a pair of spectacles. If he was unlucky enough to miss a traffic sign and the courts found out that he had ignored a recommendation from the Mediphone they would certainly increase his fine. He would have to balance the prospect of another visit to Mediphone with the risk to his pocket.

Everything this article describes is almost possible with technology available now. IBM has been developing speech recognition for several years, and Apricot incorporates a microphone into the front of its current range of computers for this reason. "Breathalysing" is perhaps most commonly used to assess alcohol excretion but many other metabolic products are excreted in the breath, and biochemical analysis generally has been carried out on smaller and smaller samples as time goes by. The various computer networked systems mentioned are all in place now, and child health systems in the regions incorporate birth registration. Speech synthesisers (as opposed to speech recognisers) are available on even the cheapest of home computers.

Whether computer aided diagnosis based on question and answer techniques will be trusted sufficiently for computers to be able to prescribe on the basis of them is more debatable. Similarly, ethical considerations and confidentiality would need to be taken into account before health computers would be allowed to link all members of the family and their medical histories together, let alone interrogate airline booking systems or credit systems. In principle they might be allowed to access these systems without any data flowing in the other direction.

Allowing computers to choose which treatment to prescribe on the basis of experience accumulated in a neural network might be similarly controversial, but it would have the advantage that the outcome of treatment in every patien living in normal circumstances would be taken into account rather than only those enrolled in the very special circumstances of a randomised controlled trial.

\section{Consultatio epistulae-the way forward?}

Epilepsy Research Group, National Hospital for Neurology and Neurosurgery, London WC1N 3BG

MC Walker, research registrar

JW A S Sander, associate specialist

Correspondence to:

Dr M C Walker,

Chalfont Centre for

Epilepsy,

Chalfont St Peter,

Bucks SL9 0RJ.

BMF 1993;307;1624-5

\section{C Walker, JW A S Sander}

Our centre receives referrals from a wide catchment area and it can be difficult for patients to get to the clinic. They often have to make long, arduous journeys for a relatively short consultation. In this context we describe a case of consultatio epistulae; we believe this is the first such case documented.

\section{Case report}

A 30 year old man with a 12 year history of intractable complex partial and secondary generalised seizures first attended the epilepsy clinic at the National Hospital for Neurology in 1989. At the beginning of January 1993 we received a letter and questionnaire from him (box) along with a stamped, addressed envelope.

\section{Comment}

We believe that with the "rationalisation" of the health service, in which hospital services are offered at centres chosen on the basis of economics rather than proximity to the patient, an epidemic of consultatio epistulae may occur. Whether this condition is detrimental to patient care is a matter of debate; it would certainly increase patient turnover in a busy clinic. Computerisation of this mode of consultation may make it possible to dispense with the services of a 